\title{
Focal segmental glomerulosclerosis with concurrent lipemic pancreatitis: A case report
}

\author{
Semih Gülle ${ }^{\circ}$, Harun Akar $[0$ \\ Department of Internal Medicine, University of Health Sciences, Izmir Tepecik Training and Research Hospital, İzmir, Turkey
}

\begin{abstract}
Nephrotic syndrome (NS) is a significant renal disease characterized by $>3 \mathrm{~g} /$ day proteinuria, hypoalbuminemia and hyperlipidemia. Although there are many causes in its etiology, hypertriglyceridemia together with focal segmental glomerulosclerosis (FSGS) is rarely encountered. In this case report, we aimed to discuss a case who presented to our clinic with lipemic pancreatitis and was found to have nephrotic syndrome associated with concurrent focal segmental glomerulosclerosis.

Keywords: Focal segmental glomerulosclerosis, hypertriglyceridemia, lipemic pancreatitis, pancreatitis.
\end{abstract}

Nephrotic syndrome (NS) is an important cause of kidney disease characterized by $>3$ g/day proteinuria, hypoalbuminemia, and hyperlipidemia. ${ }^{[1]}$ Patients with nephrotic syndrome often have complaints of generalized puffiness and shortness of breath without the presence of heart failure or severe respiratory disease. ${ }^{[2]}$ Clinical manifestations due to elevated triglyceride (TG) levels may rarely occur in patients with nephrotic syndrome. In this case report, we aimed to discuss a case who presented to our clinic with lipemic pancreatitis and was found to have nephrotic syndrome associated with concurrent focal segmental glomerulosclerosis.

\section{CASE REPORT}

A 40-year-old female patient presented to our clinic with loss of appetite, nausea, and abdominal pain for the past two days. Abdominal pain was in the right upper quadrant and was colic, radiating towards the back. Clinical history revealed hypertension and type 2 diabetes diagnosed two years ago, and the patient was using nifedipine $30 \mathrm{mg}$ daily and metformin $1,000 \mathrm{mg}$ twice daily. The patient was using her medications regularly and routinely monitored her blood sugar at home. The patient's examination revealed blood pressure: 135/80 $\mathrm{mmHg}$, pulse $90 \mathrm{bpm}$, body temperature $37^{\circ} \mathrm{C}$, and abdominal examination revealed bowel sounds were normoactive, and tenderness and voluntary guarding with palpation. Rebound was not present. The patient did not describe any recent changes in bowel movements, and she had no complaints of dysuria. The patient had pretibial pitting edema $(+++/+++)$ and peripheral pulses were palpable. Other systemic examinations were unremarkable. The patient was informed about the procedure and written consent was obtained.

Laboratory tests revealed WBC: $9,000 / \mathrm{mm}^{3}$,

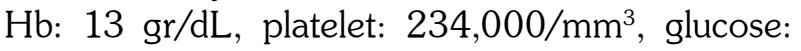
$160 \mathrm{mg} / \mathrm{dL}$, albumin: $2.1 \mathrm{gr} / \mathrm{dL}$, total protein: $5.3 \mathrm{gr} / \mathrm{dL}$, amylase: $80 \mathrm{U} / \mathrm{L}$, lipase: $350 \mathrm{U} / \mathrm{L}$, triglycerides: $1,085 \mathrm{mg} / \mathrm{dL}, \mathrm{BUN}$ : $39 \mathrm{mg} / \mathrm{dL}$,

Received: March 14, 2020 Accepted: August 27, 2020 Published online: December 16, 2020

Correspondence: Semih Gülle, MD. Dokuz Eylül Üniversitesi Tıp Fakültesi, İç Hastalıkları Anabilim Dalı, 35340 İnciraltı, İzmir, Türkiye. Tel: +90 541 - 6442466 e-mail: semih.gulle@hotmail.com 
Table 1. Laboratory findings upon presentation with acute pancreatitis and during nephrology follow-up

\begin{tabular}{|c|c|c|c|}
\hline Laboratory findings & $\begin{array}{c}\text { Admission } \\
\text { (Acute pancreatitis) }\end{array}$ & $\begin{array}{c}\text { Day } 7 \\
\text { (Nephrology ward) }\end{array}$ & $\begin{array}{c}\text { Day } 21 \\
\text { (2 weeks post-biopsy) }\end{array}$ \\
\hline Hemoglobin (mg/dL) & 10.8 & 11.1 & 10.4 \\
\hline White blood cell $\left(\times 10^{3} / \mathrm{uL}\right)$ & 9.3 & 9.2 & 8.5 \\
\hline Platelet $\left(\times 10^{3} / \mathrm{uL}\right)$ & 234 & 293 & 303 \\
\hline Glucose (mg/dL) & 160 & 105 & 126 \\
\hline Aspartate aminotransferase (U/L) & 75 & 44 & 15 \\
\hline Alanine aminotransferase (U/L) & 64 & 35 & 16 \\
\hline High density lipoprotein (mg/dL) & 47 & 49 & 45 \\
\hline $\mathrm{HbA1c}(\%)$ & 6.4 & & \\
\hline Direct-lactate dehydrogenase $(\mathrm{mg} / \mathrm{dL})$ & 125 & 110 & 115 \\
\hline Triglyceride (mg/dL) & 1,085 & 401 & 375 \\
\hline Low density lipoprotein (U/L) & 270 & 220 & 225 \\
\hline Total protein $(\mathrm{g} / \mathrm{dL})$ & 5.3 & 6.5 & 6.4 \\
\hline Albumin $(\mathrm{g} / \mathrm{dL})$ & 2.1 & 3.1 & 3 \\
\hline Globulin (g/dL) & 3.5 & 3.4 & 3.4 \\
\hline T. Bilirubin (mg/dL) & 1.4 & 1.1 & 1.2 \\
\hline D. Bilirubin (mg/dL) & 0.6 & 0.3 & 0.5 \\
\hline Amylase & 80 & 65 & 15 \\
\hline Lipase & 350 & 220 & 30 \\
\hline Blood urea nitrogen $(\mathrm{mg} / \mathrm{dL})$ & 39 & 44 & 36 \\
\hline Creatinine (mg/dL) & 1.3 & 1.1 & 1.1 \\
\hline Sodium (mmol/L) & 140 & 142 & 136 \\
\hline Potassium (mmol/L) & 4.6 & 4.8 & 4.5 \\
\hline Calcium (mg/dL) & 9.3 & 9.1 & 9 \\
\hline Phosphorous (mg/dL) & 3.7 & 3.6 & 3.8 \\
\hline Spot urine protein/creatinine & 3.6 & & 4.2 \\
\hline $24 \mathrm{~h}$ urine protein (g/day) & 5 & 4.1 & 4 \\
\hline
\end{tabular}

Hb: Hemoglobin, HbA1c: Glycated hemoglobin.

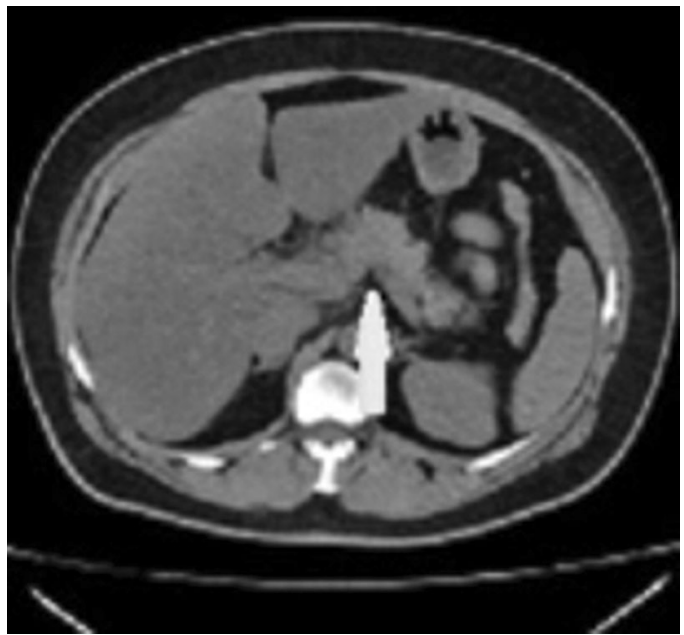

Figure 1. Abdominal computed tomography, increased pancreatic volume, striations and deposits in surrounding fatty tissue. creatinine: $1.3 \mathrm{mg} / \mathrm{dL}$, LDH: 270, AST: 75, ALT: 64, total bilirubin: $1.4 \mathrm{mg} / \mathrm{dL}$. HbA1c of the diabetic patient was $6.4 \%$ at admission. Complete urine analysis was normal except for $3+$ proteinuria. Acute pancreatitis was considered due to over tenfold increase in plasma lipase levels and computed tomography (CT) was performed. Abdominal CT revealed increased pancreatic volume, and striations in the surrounding fatty tissue. No pathology was observed in other intraabdominal organs (Table 1 and Figure 1).

The patient was diagnosed with acute pancreatitis and hospitalized. Lipemic pancreatitis was considered in the patient who had triglyceride level of $1,085 \mathrm{mg} / \mathrm{dL}$ and no gallbladder stones. Oral intake was discontinued. Intravenous fluid resuscitation, IV controlled insulin infusion, 



Figure 2. (a) In kidney biopsy, 8 glomeruli were observed, and global sclerosis in 2 glomeruli and focal segmental sclerosis in a few remaining glomeruli. (b) Focal tubular atrophy is observed. (c) In immunofluorescence examination, IgA (+/-), IgM $(+/++)$, IgG (-), c1q (-), C3 (++/++), Fibrinogen (-).

non-opioid analgesia, and $\mathrm{H} 2$ receptor blockers were given. The patient's Ranson criteria at admission and at 48 hours was low, and with clinical improvement, low-fat diet and $267 \mathrm{mg}$ fenofibrate daily was initiated.

After clinical improvement, the patient was transferred to the nephrology ward for her proteinuria and hyperlipidemia. Nephrotic syndrome was considered due to hypoalbuminemia, $7 \mathrm{~g}$ /day proteinuria in 24 -hour urine test, and hyperlipidemia. The patient's tests revealed HbsAg (-), Anti HbsAg (-), Anti HIV (-), and Anti $\mathrm{HCV}(-)$. Immunological markers were ANA (-) and ANCA (-), and complement levels were normal. Her body mass index was $26 \mathrm{~kg} / \mathrm{m}^{2}$ and she had no history of smoking, substance use, NSAID use, or bisphosphonate use. After complete recovery of acute pancreatitis, her symptoms persisted for three weeks; the patient was informed and kidney biopsy was performed.

The result of the patient's kidney biopsy was consistent with segmental glomerulosclerosis. The patient's current status was evaluated as primary FSGS (Figure 2). Considering all of the patient's clinical features as a whole, the patient was considered NS secondary to primary FSGS and acute lipemic pancreatitis induced by previous hyperlipidemia. With the results of the kidney biopsy, the patient was initiated ACE-I at proper dosage and proteinrich diet. The patient's blood sugar regulation was inadequate, and $30 \mathrm{mg}$ glicazide SR was added to metformin treatment. At one-month follow-up, the patient's albumin levels were improved and proteinuria decreased, and TG level was $400 \mathrm{mg} / \mathrm{dL}$.

\section{DISCUSSION}

Focal segmental glomerulosclerosis is the second most common cause of NS in adults. Although secondary FSGS is common, it is referred to as primary FSGS to a lesser extent when no definite cause is found. ${ }^{[3]}$ In our patient, primary FSGS was mainly considered since diabetes was regulated and there were no remarkable characteristics of risk factors. Shortness of breath and generalized edema due to hypoproteinemia are common symptoms in NS and significant clinical response can be achieved with proper treatment in the early term. ${ }^{[3]}$ Less common findings of NS are clinical symptoms associated with coagulation disorders and hyperlipidemia.

While hyperlipidemia in nephrotic syndrome often presents clinical signs together with elevated LDL and VLDL, severely elevated TG is also rarely seen. This is thought to be due to reduced lipoprotein lipase activity. ${ }^{[4]}$ To the best of our knowledge, our patient was the first case of FSGS and NS coexistence presenting as lipemic pancreatitis. Early evaluation of signs and symptoms may allow early diagnosis of a disease as significant as NS, and potential complications can be avoided with proper treatment.

\section{Declaration of conflicting interests}

The authors declared no conflicts of interest with respect to the authorship and/or publication of this article.

\section{Funding}

The authors received no financial support for the research and/or authorship of this article. 


\section{REFERENCES}

1. Ozturk S, Sumnu A, Seyahi N, Gullulu M, Sipahioglu M, Artan S, et al. Demographic and clinical characteristics of primary glomerular diseases in Turkey. Int Urol Nephrol 2014;46:2347-55.

2. Kodner C. Diagnosis and Management of Nephrotic Syndrome in Adults. Am Fam Physician
2016;93:479-85.

3. Sethi S, Zand L, Nasr SH, Glassock RJ, Fervenza FC. Focal and segmental glomerulosclerosis: clinical and kidney biopsy correlations. Clin Kidney $\mathrm{J}$ 2014;7:531-7.

4. Sato T, Liang K, Vaziri ND. Down-regulation of lipoprotein lipase and VLDL receptor in rats with focal glomerulosclerosis. Kidney Int 2002;61:157-62. 